\title{
Promoter hypermethylation of tumor suppressor genes correlates with tumor grade and invasiveness in patients with urothelial bladder cancer
}

\author{
Shumaila M Bilgrami ${ }^{1}$, Sohail A Qureshi ${ }^{2}$, Shahid Pervez ${ }^{3}$ and Farhat Abbas ${ }^{4^{*}}$
}

\begin{abstract}
Purpose: To investigate the promoter methylation status at selected loci which encode for key proteins involved in apoptosis, DNA repair, cell cycle control and progression in urothelial cell carcinoma of bladder and compare the findings from tissue samples with that of plasma.

Methods: Total genomic DNA was isolated from 43 non-muscle invasive (low grade) and 33 muscle invasive (high grade) urothelial bladder cancer samples along with 10 control cases of normal bladder mucosa. Promoter methylation status was investigated for RASSF1A, APC, MGMT, CDKN2A and CDKN2B genes using real-time methylation-specific PCR with $S Y B R^{\circledast}$ green. Plasma samples from 16 patients with muscle invasive high grade bladder cancer were also subjected to similar analyses.

Results: Promoter hypermethylation was frequently observed in RASSF1A, APC and MGMT gene promoters ( $p$-value $<0.001)$. The methylation was more prominent in the muscle invasive high grade bladder cancer when compared to non-muscle invasive low grade group ( $p$-value $<0.001)$ and normal bladder mucosa $(p$-value $<0.05)$. The RNA expression of RASSFIA, APC and MGMT was also found to be decreased in the muscle-invasive high grade bladder cancer when compared to the non muscle invasive low grade group ( $p$-value $<0.05$ ). RASSF $1 A$, MGMT and CDKN2A showed comparable results when data from 16 plasma samples was compared to the corresponding tissue samples.
\end{abstract}

Conclusion: Our results suggest that epigenetic silencing of RASSFIA, APC and MGMT genes is strongly associated with invasive high grade urothelial bladder cancer. Thus, status of promoter methylation has the potential to serve as valuable tool for assessing aggressiveness of urothelial cell carcinoma of bladder.

Keywords: Promoter methylation; Tumor suppressor genes; Paraffin embedded tissue; Plasma; Urothelial cell carcinoma of bladder

\section{Background}

Urinary bladder cancer represents the second most frequent urologic cancer worldwide which accounts for $3.3 \%$ of newly diagnosed cancer cases and $2.1 \%$ of cancer deaths. Globally, the incidence of bladder cancer is highest among North American and Western European populations $(<16.2$ per 100,000); in comparison Eastern

\footnotetext{
* Correspondence: farhat.abbas@aku.edu

${ }^{4}$ Department of Surgery, Aga Khan University, Stadium Road, Karachi 74800, Pakistan

Full list of author information is available at the end of the article
}

Europe \& Asian countries have relatively lower rates $(<1.7$ per 100,000). Alarmingly, Pakistan carries a heavy burden of disease among all South Central Asian countries with mortality rate of 3.8 and 1.1 per 100,000 in males and females, respectively (IARC 2013).

At present, cystoscopy followed by histological examination serve as the gold standard for making the initial diagnosis and monitoring progression of bladder tumors. Although cystoscopy provides valuable information regarding tumor status, it involves an invasive procedure which is not very cost effective. In view of this, there is a 
dire need to identify robust genetic and/or epigenetic markers that can serve as reliable indicators of disease. Over the past two decades a number of biomarkers such as nuclear matrix protein 22 (NMP22), fibrin degradation product (Fibrin/FDP), bladder tumor antigen (BTA), high molecular weight carcinoembryonic antigen and mucin have been identified and approved by FDA for monitoring and screening of bladder cancers but initial enthusiasm for their clinical utility waned quickly because each of them lacked specificity, reproducibility as well as sensitivity (Ludwig and Weinstein 2005).

DNA methylation negatively influences transcription and plays a pivotal role in shaping the epigenome to ascertain accurate temporal and spatial expression of genes during development. It occurs in distinct regions of promoters where the density of the dinucleotide CpG is higher than would be expected in random sequence. These so called "CpG islands" are found in over $60 \%$ of the human genes. The process of converting an unmodified $\mathrm{CpG}$ into one which is methylated at the $\mathrm{C} 5$ position of cytosine is catalyzed by DNA methyltransferases (DNMT). DNMT1 uses hemi-methylated CpG resides as substrate and fully methylates them. In contrast, DNMT3 is capable of methylating unmodified CpG dinucleotides de novo. Since DNA hypermethylation serves as a powerful mechanism that turns off gene transcription any unprogrammed changes in the epigenome - be it hypermethylation of a tumor suppressor genes (TSGs) or demethylation of oncogenes - are likely to culminate in a disease state. Indeed, silencing of tumor suppressor genes due to CpG hypermethylation has been well documented in different types of cancers. In bladder cancer, expression and function of a number of TSGs including PTCH, TSC1, RB1, PTEN, p53, DAPK, FHIT, CDH1, $C D K N 2 B, C D K N 2 A, A P C, R A S S F 1 A$ and MGMT are known to be impacted either by physical changes in the sequence of DNA or by un-programmed DNA methylation (Cairns 2007; Knowles 2007).

In this study we have investigated the DNA methylation status of a panel of tumor suppressor genes that include RASSF1A, APC, MGMT, CDKN2A and CDKN2B using formalin fixed paraffin embedded (FFPE) biopsies obtained from individuals suffering from non- muscle invasive and muscle invasive urothelial cell carcinoma of bladder from Pakistan. Normal bladder mucosa/benign urologic disease samples were used as controls. These genes were selected because their respective products influence cell cycle control, apoptosis and DNA repair, and because they have been found to be epigenetically silenced in many human neoplasms.

\section{Results}

Our study included 76 patients with transitional cell carcinoma of bladder from which 43 were non-muscle invasive tumors (pTa-T1) and 33 muscle invasive tumors $(\geq \mathrm{pT} 2)$. Transitional cell carcinoma was low grade (including papillary urothelial neoplasm of low malignant potential) in 43 patients and high grade in 33 patients. The median age of patients was 64 years in non-invasive low grade cancer group and 61 years in invasive high grade bladder cancer. Methylation analyses were also carried out in 10 patients with benign urologic disease as control group with a median age of 49 years. Details of the individuals whose tissues were used in this study are listed in Table 1.

Genomic DNA from the 76 FFPE diseased as well as 10 control tissues was isolated, modified by bisulfite reagent and subsequently used as template for carrying out methylation-specific real-time PCR analysis using pairs of gene-specific primer sets. This revealed that the prevalence of promoter hypermethylation in all five tumor suppressor genes was higher in the muscle invasive high grade urothelial bladder cancer as compared to the non-muscle invasive low grade group (Table 2).

Out of the five tumor suppressor genes studied in the normal bladder mucosa, muscle invasive and non-muscle invasive urothelial bladder cancer, the promoter hypermethylation at RASSF1A, APC and MGMT was statistically significant ( $<0.001$; Table 3$)$. Unexpectedly, RASSF1A promoter was also found to be hypermethylated in 5 ( 2 females and 3 males) out of 10 normal bladder mucosa samples.

\section{Comparison of normalized index of methylation}

Normalized index of methylation (NIM) for all the tumor suppressor genes in the cancer and control group was calculated. The NIM serves as an index of the percentage of bisulfite converted input copies of DNA that

Table 1 Clinicopathological parameters of normal and bladder Cancer FFPE samples

\begin{tabular}{lccc}
\hline Parameter & $\begin{array}{c}\text { Low grade } \\
\text { urothelial } \\
\text { cancer }\end{array}$ & $\begin{array}{c}\text { High grade } \\
\text { urothelial } \\
\text { cancer }\end{array}$ & $\begin{array}{c}\text { Normal } \\
\text { bladder } \\
\text { mucosa }\end{array}$ \\
\hline Number of patients & 43 & 33 & 10 \\
Males & $37(86 \%)$ & $26(78 \%)$ & 05 \\
Females & $06(14 \%)$ & $07(21 \%)$ & 05 \\
Age & & & \\
Median (Inter-quartile range) & $64(50-73)$ & $61(53-68)$ & $49(40-59)$ \\
$\quad$ Pathologic stage & & & \\
$\quad$ pTa-pT1 & & & \\
$\quad$ 2pT2 & 43 & 33 &
\end{tabular}

(pTa: Non-invasive papillary carcinoma, pT1: Tumor invades sub epithelial connective tissue, pT2: Tumor invades muscle, pT3: Tumor invades perivesical tissue, pT4: Tumor invades any of the following: prostate, uterus, vagina, pelvic wall, abdominal wall). 
Table 2 Frequency of hypermethylation of tumor suppressor gene loci in urothelial bladder cancer samples

\begin{tabular}{lcc}
\hline $\begin{array}{l}\text { Tumor } \\
\text { suppressor } \\
\text { gene }\end{array}$ & $\begin{array}{l}\text { Low grade urothelial } \\
\text { carcinoma of urinary } \\
\text { bladder (TCC) } \mathbf{n}=\mathbf{4 3}\end{array}$ & $\begin{array}{c}\text { High grade urothelial } \\
\text { carcinoma of urinary } \\
\text { bladder (TCC) } \mathbf{n}=\mathbf{3 3}\end{array}$ \\
\hline RASSF1A & $49 \%(21 / 43)$ & $82 \%(27 / 33)$ \\
APC & $51 \%(22 / 43)$ & $97 \%(32 / 33)$ \\
MGMT & $93 \%(41 / 43)$ & $94 \%(31 / 33)$ \\
CDKN2A & $19 \%(8 / 43)$ & $24 \%(8 / 33)$ \\
CDKN2B & $37 \%(16 / 43)$ & $57 \%(19 / 33)$ \\
\hline
\end{tabular}

are fully methylated at the primer binding sites. However, it is important to note that the NIM maybe $>1$ if the copies of Actin are deleted relative to the gene of interest, or copies of the gene of interest are gained relative to Actin in any given sample.

When the mean normalized index of methylation of the genes was compared between non- muscle invasive low grade and muscle invasive high grade urothelial bladder cancer, the degree of hypermethylation was more prominent in the muscle invasive high grade group for RASSF1A, APC and MGMT $(p<0.001)$. However, only $A P C$ and MGMT showed significance $(p<0.001)$ in the muscle invasive high grade bladder cancer when it was compared with the normal bladder mucosa (Figure 1).

Table 3 Normalized index of methylation (NIM)\% and corresponding $\mathbf{p}$-values

RASSF1A APC MGMT CDKN2A CDKN2B

\begin{tabular}{|c|c|c|c|c|c|}
\hline \multicolumn{6}{|c|}{$\begin{array}{l}\text { Invasive high grade } \\
\text { urothelial bladder } \\
\text { cancer }(n=33)\end{array}$} \\
\hline Mean & 40 & 6.1 & 9 & 0.09 & 0.58 \\
\hline Range & $0-270$ & $0-50$ & $0-96$ & $0-2$ & $0-6$ \\
\hline \multicolumn{6}{|c|}{$\begin{array}{l}\text { Non-invasive low } \\
\text { grade urothelial } \\
\text { bladder cancer } \\
(n=43)\end{array}$} \\
\hline Mean & 2 & 2 & 2.3 & 0.4 & 0.1 \\
\hline Range & $0-49$ & $0-43$ & $0-41$ & $0-8$ & $0-2$ \\
\hline \multicolumn{6}{|c|}{$\begin{array}{l}\text { Normal bladder } \\
(n=10)\end{array}$} \\
\hline Mean & 2 & 0 & 0 & 1 & 2 \\
\hline Range & $0-12$ & 0 & $0-4$ & 0-16 & $0-1$ \\
\hline${ }^{*}$ p-value & $<0.001$ & $<0.001$ & $<0.001$ & 0.748 & 0.114 \\
\hline \multicolumn{6}{|c|}{$\begin{array}{l}\text { Plasma samples } \\
(n=16)\end{array}$} \\
\hline Mean & 24.9 & 0.035 & 16.2 & 1.5 & 5.9 \\
\hline Range & $3-125$ & $0-4.4$ & $\begin{array}{l}0.1- \\
111.7\end{array}$ & $0-16.3$ & $0.1-18.9$ \\
\hline${ }^{* *}$ p-value & 0.539 & $<0.001$ & 0.524 & 0.215 & $<0.01$ \\
\hline
\end{tabular}

*Kruskal Wallis Test **Paired $T$-Test ( $\mathrm{p}$-value $<0.01)$.
Interestingly, none of the tumor suppressor genes reached statistical significance when NIM was compared between normal bladder mucosa and non-muscle invasive low grade bladder cancer (Table 4).

\section{Change in mRNA expression}

NIM was found to be higher for RASSF1A, APC and $M G M T$ in muscle invasive high grade urothelial bladder cancer as compared to the non muscle invasive low grade cancer. In order to determine any difference in the gene expression between the two groups, total RNA was extracted from formalin fixed and paraffin embedded samples, was reverse transcribed and amplified using specific primers. The mRNA expression of RASSF1A, $A P C$ and MGMT was found to be decreased in the muscle invasive high grade urothelial cell carcinoma of bladder as compared to the non- muscle invasive low grade group (Figure 2), and this finding was statistically significant ( $\mathrm{p}$-value $<0.05$ ) when Wilcoxon signed rank test was applied.

\section{Association between biopsy and plasma samples}

In the next step, to assess whether there is an association between the promoter methylation patterns detected in tissue samples with those in blood samples, promoter hypermethylation at the tumor suppressor genes was also determined in sixteen plasma samples from patients with invasive high grade urothelial bladder cancer. When the results were statistically analyzed using paired- $T$ test, RASSF1A, MGMT and CDKN2A showed comparable results in the cancer tissue and plasma samples. Whereas, $A P C(p<0.01)$ and $C D K N 2 B(p<0.05)$ showed significant difference between the two.

\section{Survival analysis}

By Kaplan-Meier analysis, the methylation status of genes did not show any significance in correlation with the recurrence-free interval. However, a pattern was observed with worse recurrence free survival in methylation positive urothelial cell carcinoma of bladder. When the overall survival was correlated with the methylation status of candidate tumor suppressor genes, it was found to be significantly shorter in patients with RASSF1A and $A P C$ methylation positive tumor (Figure 3).

\section{Discussion}

In the present study, we have investigated the promoter methylation status of candidate tumor suppressor genes namely RASSF1A, APC, MGMT, CDKN2A and CDKN2B in normal bladder mucosa, invasive high grade and noninvasive low grade urothelial bladder cancer using formalin fixed paraffin embedded tissue and plasma samples.

Our results demonstrate that the prevalence of promoter methylation was higher in invasive high grade 

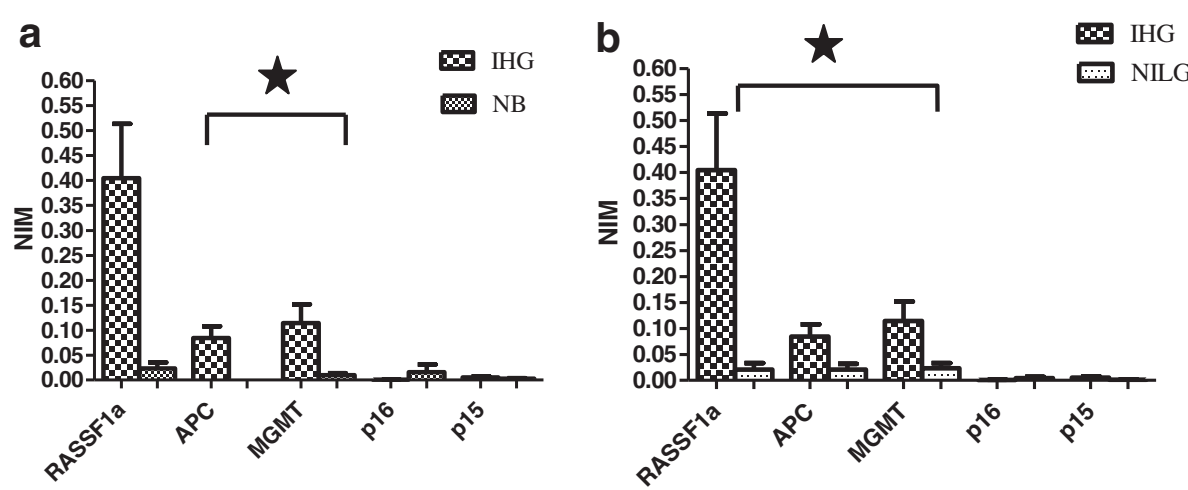

Figure 1 Comparison of Normalized index of methylation (NIM) for the tumor suppressor genes. a Between normal bladder mucosa (NB) and muscle invasive high grade (IHG) urothelial bladder cancer (*p-value for APC and MGMT was <0.001) b Between muscle invasive high grade (IHG) and non-muscle invasive low grade (NILG) urothelial bladder cancer ( ${ }^{*}$ p-value for RASSFIA, APC and MGMT was $<0.001$ each-*Mann-Whitney- $U$ Test).

urothelial bladder cancer as compared to the noninvasive low grade. Out of the five genes studied the prevalence of hypermethylation was $82 \%, 97 \%$ and $94 \%$ for RASSF1A, APC and MGMT, respectively. Interestingly, the findings from formalin fixed paraffin embedded samples were comparable to the plasma samples of invasive high grade bladder cancer patients for CDKN2A, MGMT and RASSF1A.

The RASSF1 (Ras association domain family 1 ) family represents a class of Ras effector proteins that have tumor suppressor properties. RASSF1A acts as a putative tumor suppressor gene located on 3p21 and may serve as an effector that mediates the apoptotic effects by binding Ras in a guanosine triphosphate-dependent manner (Hesson et al. 2007). Studies have shown that as compared to the classic mutations, promoter hypermethylation serve as major mechanism of gene silencing in RASSF1A.

Promoter methylation induced silencing of RASSF1A has been found to be associated with multiple human cancers (Bhagat et al. 2012; Jiang et al. 2012; Koutsimpelas et al. 2012; Munoz et al. 2012; Jeronimo et al. 2004). Previous studies have shown that RASSF1A methylation was detectable in body fluids including plasma, nipple aspirate, sputum, urine and bronchoalveolar lavage (Dulaimi et al. 2004; Krassenstein et al. 2004; Topaloglu et al. 2004; Belinsky et al. 2005; Hoque et al. 2006).

Table 4 Comparison of NIM and corresponding p-values

\begin{tabular}{lccccc}
\hline & RASSF1A & APC & MGMT & CDKN2A & CDKN2B \\
\hline *NN vs. NILG & 0.03 & 0.04 & 1.00 & 0.61 & 0.17 \\
NB vs. IHG & 0.04 & $<\mathbf{0 . 0 0 1 *}$ & $<\mathbf{0 . 0 1 *}$ & 0.58 & 1.00 \\
NILG vs. IHG & $<0.001 *$ & $<\mathbf{0 . 0 0 1}^{*}$ & $<\mathbf{0 . 0 0 1 *}$ & 0.72 & 0.05
\end{tabular}

*Mann-Whitney- $U$ Test ( $p$-value $<0.01$, after correction for multiple testing); ${ }^{* *} \mathrm{NB}=$ Normal bladder mucosa, $\mathrm{sNILG}=$ Non-muscle invasive low grade urothelial bladder cancer; IHG = Muscle invasive high grade urothelial bladder cancer).
In bladder cancer, RASSF1A methylation has been linked to high grade bladder tumors and poor prognosis (Gao et al. 2012; Meng et al. 2012; Maruyama et al. 2001). We also found RASSF1A methylation in five out of ten normal bladder mucosa samples, which is in agreement with other studies. But this finding would raise questions about its utility as a biomarker due to low specificity; hence, studies on larger sample size are needed to address this issue.

Mutations in APC (Adenomatous polyposis coli) gene are known to be associated with Familial adenomatous polyposis coli and colorectal cancer. $A P C$ protein acts as a negative regulator of $\mathrm{WNT} / \beta$-catenin signaling pathway as it promotes the proteolytic degradation of $\beta$-catenin in Wnt signaling pathway. It also plays a role in cell migration and adhesion, apoptosis and transcriptional activation (Klaus and Birchmeier 2008).

As an interesting finding hypermethylation of $A P C$ gene promoter was more prominent in invasive high grade urothelial bladder cancer as compared to noninvasive low grade one which is also in line with the previous studies correlating $A P C$ methylation with tumor grade, stage and muscle invasion (Berrada et al. 2012; Hoque et al. 2006).

MGMT gene encodes an enzyme called O-6-Methylguanine DNA methyltransferase which removes a carcinogenic DNA lesion, $\mathrm{O}$ (6)-alkyl-guanine. The promoter methylation at MGMT has been reported in many human cancers but found to be less frequent in bladder cancer. (Bhagat et al. 2012; Koutsimpelas et al. 2012; Liu et al. 2011; Yates et al. 2007) Our study shows a prominent MGMT hypermethylation in the invasive high grade bladder cancer as well as the non-invasive low grade cancer and the findings were correlated in the plasma samples. However, the the methylation index was higher in the invasive high grade urothelial bladder cancer. 


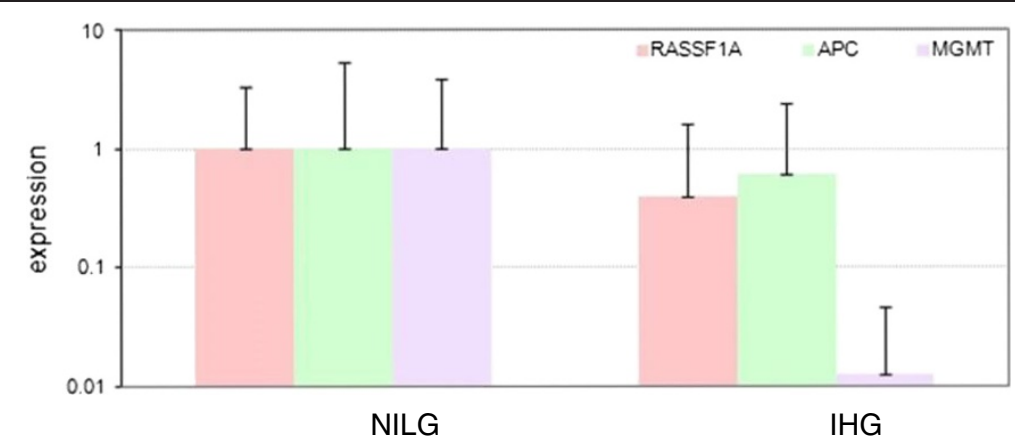

Figure 2 RNA Expression of tumor suppressor genes RASSF1A, APC and MGMT in non muscle invasive low grade (NILG) and muscle invasive high grade (IHG) urothelial cell carcinoma of bladder. Total RNA was extracted from formalin fixed and paraffin embedded samples, was reverse transcribed and amplified using primers against RASSF1a, APC and MGMT to determine any difference in the expression of RNA. (p-value for RASSFIA, APC and MGMT was $<0.05$ each-when Wilcoxon signed rank test was applied).

Impaired regulation of cell cycle control is an important event in tumorigenesis. The regulation of cell cycle involves multiple check points including cyclins, cyclin dependent kinase enzymes and cyclin dependent kinase inhibitors. Cyclin dependent kinase inhibitor 2A and 2B, $p 16$ and $p 15$ respectively, act as negative regulators of cell cycle progression and thus are potential tumor suppressors $p 16 /$ cyclin-dependent kinase inhibitor $2 A$ (CDKN2A) encodes splice variants and is involved in sequestering MDM2 so $p 53$ gets stabilized. It inhibits enzyme CDK4 kinase, hence inhibits progression of cell cycle from G1 phase.

Studies on $C D K N 2 A / p 16$ promoter methylation in bladder cancer have shown varying results reporting the frequency of methylation ranging from 7-60\% (Chan, Chan et al. 2002; Dominguez et al. 2002; Chang et al. 2003; Catto et al. 2005). In our study, the overall methylation frequency for $C D K N 2 A / p 16$ was low in both invasive high grade $(24 \%)$ and non-invasive low grade (19\%) urothelial bladder cancer with a very low normalized index of methylation. However, the results were found to be analogous when the $C D K N 2 A / p 16$ methylation found in paraffin embedded samples was compared to the plasma samples.

Like $p 16, p 15 /$ cyclin-dependent kinase inhibitor 2B $(C D K N 2 B)$ also encodes a cyclin dependent kinase inhibitor which inhibits CDK4 or CDK6 kinases and prevents the cell cycle progression from G1 phase. Significant promoter hypermethylation has been reported for both $C D K N 2 A$ and $C D K N 2 B$ in cervical cancer patients of North Indian origin (Jha et al. 2012).

Promoter methylation at $C D K N 2 B / p 15$ is not frequent in bladder cancer, as previous studies have reported a methylation frequency ranging from $0-13 \%$ (Le Frere-Belda et al. 2001). Our results have shown that $C D K N 2 B$ promoter methylation was slightly higher than $C D K N 2 A$ but the findings of $C D K N 2 B$ methylation from paraffin embedded sample were not comparable to the plasma samples.

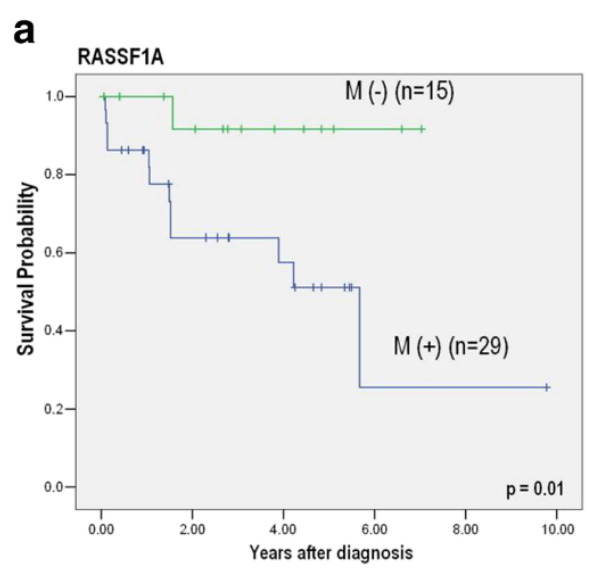

\section{b}

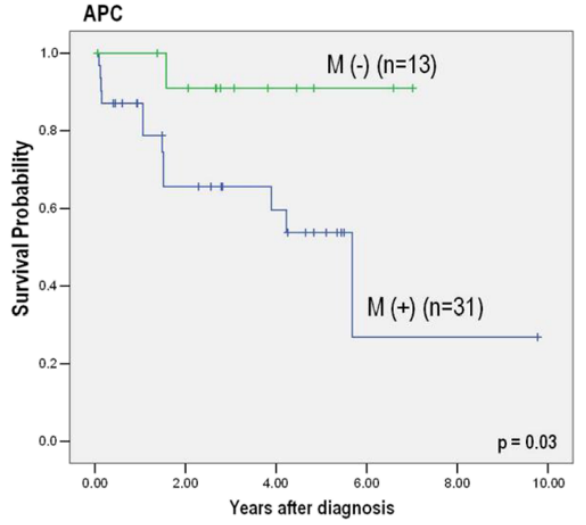

Figure 3 Association of patients' survival and promoter methylation status by Kaplan-Meier method. a survival curves by methylation status of RASSFIA (Number of censored cases with and without methylation were 17 and 14, respectively) b survival curves by methylation status of APC (Number of censored cases with and without methylation were 19 and 12, respectively). 


\section{Conclusion}

To summarize, our study demonstrates that promoter hypermethylation in tumor suppressor genes plays an important role in bladder cancer development and progression which is evident from the finding that methylation of some tumor suppressor genes associates well with tumor grade, invasiveness and patient's survival.

Although much has been published in this regard but data from developing world is lacking. This study, though involving some preliminary results on plasma samples, is the first of its kind on a south central Asian population. If the findings are validated using larger number of samples, it could serve as a rapid tool for assessing aggressiveness of bladder cancer in the Pakistani population.

However, to select an ideal gene panel that is specific for bladder cancer still remains a critical issue for designing the most useful panel of epigenetic biomarkers that can come into clinical practice for an early diagnosis or monitoring the progression of disease.

\section{Methods \\ Samples}

This study was approved by the Ethical Review Committee of The Aga Khan University and all samples used or collected followed the approved protocol. Source of bladder cancer tissues were the 76 formalin fixed paraffin embedded blocks prepared from tissue obtained from patients who underwent cystoscopy and/or transurethral resection of bladder tumor (TURBT) during 2008-2012. Blocks with $>70 \%$ cancerous tissue were selected after histological examination of slides and categorized into non-muscle invasive low grade and muscle invasive high grade urothelial bladder cancer. In addition, 10 blocks of benign bladder mucosa with no evidence of malignancy were obtained from patients who underwent cystoscopy and bladder biopsy during 2007-2012 for different urinary complaints; these served as control (Figure 4). Approximately $5 \mathrm{ml}$ of venous blood sample was also collected from 10 age matched healthy individuals and 16 patients with invasive high grade urothelial bladder cancer who underwent cystoscopy and/or TURBT in 2012.

\section{DNA extraction from FFPE samples}

DNA was extracted from formalin-fixed paraffin embedded (FFPE) blocks using QIAamp DNA FFPE tissue kit (Qiagen). Briefly, around 5-7 sections of 5-10 $\mu \mathrm{m}$ thickness were cut from block with microtome (Leica Inc.) and collected in an eppendorf tube. Tissue sections were deparaffinized by adding $1 \mathrm{ml}$ xylene to the sample, tube was vortexed vigorously and then centrifuged at 14,000 rpm for 2 minutes at room temperature. Supernatant was removed and $1 \mathrm{ml}$ of ethanol was added (to remove residual xylene from the sample), mixed by vortexing and centrifuged at $14,000 \mathrm{rpm}$ for 2 minutes at room temperature. Supernatant was removed and the pellet air dried at $37^{\circ} \mathrm{C}$ until residual ethanol had evaporated. Tissue samples were homogenized in the Buffer ATL $(180 \mu \mathrm{l})$ provided in the kit. Homogenized tissue samples were subjected to digestion by adding $20 \mu \mathrm{l}$ proteinase- $\mathrm{K}$ at a concentration of $10 \mathrm{mg} / \mathrm{ml}$, mixed by vortexing and tube incubated at $56^{\circ} \mathrm{C}$ for 1 hour to ensure complete tissue lysis. To reverse the formaldehyde modification of nucleic acids, tubes were incubated at $90^{\circ} \mathrm{C}$ for 1 hour. DNA was placed in a spin column, washed in situ, and eluted in $50 \mu \mathrm{l}$ TE buffer. This DNA was quantitated by Nanodrop ND-1000 Spectrophotometer (Thermo Scientific). About 1-2 $\mu \mathrm{g}$ of DNA with A260:A280 > 1.8 was subjected to bisulfite modification using EpiTect ${ }^{\circ}$ Bisulfite kit (Qiagen) following manufacturer's protocol.

\section{DNA extraction from plasma}

DNA was extracted from plasma samples using QIAamp ${ }^{\circ}$ DNA Blood Mini kit (Qiagen) following manufacturer's instructions. Briefly, $200 \mu \mathrm{l}$ of plasma sample was added to a microcentrifuge tube containing $20 \mu \mathrm{l}$ Proteinase $\mathrm{K}$ and was mixed thoroughly by pipetting. Lysis buffer AL $(200 \mu \mathrm{l})$ was added to this mixture and incubated at $56^{\circ} \mathrm{C}$ for 10 minutes after thorough vortexing. The tubes were centrifuged briefly, and absolute ethanol $(200 \mu \mathrm{l})$ was added to the sample, pulse vortexed for 15 seconds and centrifuged briefly. The entire mixture was applied to the QIAamp Mini spin column in a $2 \mathrm{ml}$ collection tube (provided in the kit). The columns were centrifuged at $8000 \mathrm{rpm}$ for 1 minute, flow through was discarded and columns were placed on to new collection tubes. Two washings were done with $500 \mu \mathrm{l}$ buffer AW1 and AW2, filtrate was discarded and columns were placed on new collection tubes. QIAamp Mini spin columns were placed in a new $1.5 \mathrm{ml}$ microcentrifuge tube, $200 \mu \mathrm{l}$ buffer $\mathrm{AE}$ was added to the spin column and was incubated at room temperature $\left(15-25^{\circ} \mathrm{C}\right)$ for 5 minutes, and then centrifuged at $8000 \mathrm{rpm}$ for 1 minute to elute the DNA. The DNA samples were quantitated by Nanodrop ND-1000 Spectrophotometer (Thermo Scientific) and only samples with good concentration and nucleic acid/protein ratio $>1.8$ were processed further to bisulfite conversion.

\section{Bisulfite conversion}

Sodium bisulfite conversion of genomic DNA extracted from paraffin embedded blocks and plasma samples were carried out using EpiTect Bisulfite kit (Qiagen) as per manufacturer's protocol. Bisulfite reactions were carried out in $200 \mu \mathrm{l} \mathrm{PCR}$ tubes on Mastercycler (Eppendorf) using the following conditions: $95^{\circ} \mathrm{C}$ for $5 \mathrm{~min}, 60^{\circ} \mathrm{C}$ for $25 \mathrm{~min}, 95^{\circ} \mathrm{C}$ for $5 \mathrm{~min}, 60^{\circ} \mathrm{C}$ for $85 \mathrm{~min}, 95^{\circ} \mathrm{C}$ for $5 \mathrm{~min}$, and $60^{\circ} \mathrm{C}$ for $59 \mathrm{~min}$. 

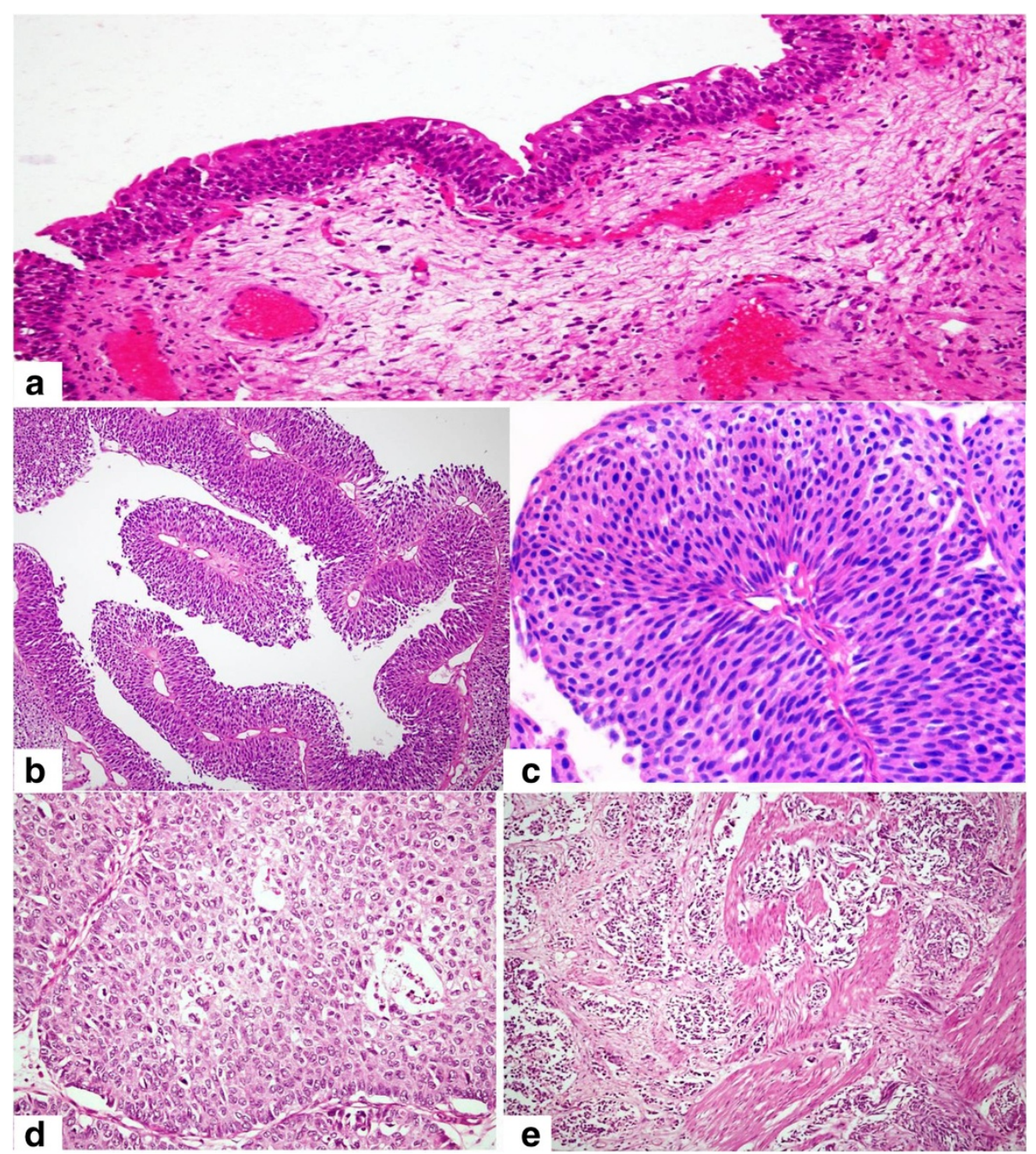

Figure 4 H \& E Staining. a Normal urothelium, b and c Non muscle invasive and low grade Urothelial cell carcinoma of bladder 10X and 20X respectively, $\mathbf{d}$ High grade Urothelial cell carcinoma of bladder, e Muscle invasion in high grade Urothelial cell carcinoma of bladder.

Subsequently, purification of DNA was carried out by adding $310 \mu \mathrm{l}$ of freshly prepared Buffer BL containing $10 \mu \mathrm{g} / \mathrm{ml}$ of carrier RNA and vortexing. Then $250 \mu \mathrm{l}$ of ethanol was added and vortexed for 15 seconds. The entire mixture was transferred to EpiTect spin column and centrifuged at 14,000 rpm for 1 minute. Then $500 \mu \mathrm{l}$ of Buffer BD (desulfonation buffer) was added and column was incubated for $15 \mathrm{~min}$ at room temperature. After washing by $500 \mu \mathrm{l}$ of Buffer BW, DNA was eluted by addition of $20 \mu \mathrm{l}$ of buffer EB and centrifuged at $14,000 \mathrm{rpm}$ for 1 minute. Bisulfite converted DNA was stored at $-20^{\circ} \mathrm{C}$ until use.

\section{Methylation-specific PCR}

Promoter methylation analysis at RASSF1A, APC, MGMT, $C D K N 2 A$ and $C D K N 2 B$ was carried out with bisulfite converted DNA on Chromo-4 cycler (Bio-Rad) with Maxima
SYBR Green Master mix (Fermentas) as the intercalating dye. Primer sequences are given in Additional file 1: Table S1. The following thermal cycling conditions were used: $95^{\circ} \mathrm{C}$ for $10 \mathrm{~min}$, followed by 44 cycles of $95^{\circ} \mathrm{C}$ for $15 \mathrm{sec}$, and $60^{\circ} \mathrm{C}$ for $1 \mathrm{~min}$. Melting curve was obtained from $65^{\circ} \mathrm{C}$ to $90^{\circ} \mathrm{C}$.

Approximately $10 \mathrm{ng}$ of methylated and bisulfite converted human DNA (Epitect ${ }^{\circ}$ Control DNA, Qiagen) was used as control in which, complete in vitro methylation of the control DNA was achieved using Sss1 methylase and Bisulfite conversion of control DNA was achieved using the EpiTect Bisulfite kit. The housekeeping gene $\beta$-actin was used as the normalization control.

All samples were run in duplicate. Data was generated on Opticon Monitor 3 software (Bio-Rad). The software GENEX 5 was used to analyze the results. Samples with Ct value $<35$ were considered as positive. 


\section{Normalized index of methylation}

The Ct value of each gene was related to its copy number and Normalized index of methylation (NIM) was calculated as the ratio of copy number of gene of interest in the sample to that of control and both were normalized to the copy number of housekeeping gene i.e.;

$$
\mathrm{NIM}=\left[\left(\text { Gene }_{\text {Sample }}\right) /\left(\text { Gene }_{\text {Control }}\right)\right] /\left[\left(\text { Actin }_{\text {Sample }}\right) /\left(\text { Actin }_{\text {Control }}\right)\right]
$$

Where, (Gene Sample) is the number of fully methylated copies of the gene of interest in a given sample, (Gene Control) is the number of fully methylated copies of the gene of interest in the SssI universally methylated control DNA, (Actin Sample) is the number of Actin copies in a given sample, and (Actin Control) is the number of Actin copies in the SssI universally methylated DNA.

\section{RNA extraction from FFPE samples}

RNA was extracted from paraffin embedded blocks using RNeasy ${ }^{\circ}$ FFPE kit (Qiagen) according to manufacturer's protocol. Briefly 5-10 sections of $5 \mu$ m thickness were cut from the paraffin embedded blocks with microtome (Leica Inc.). After paraffin removal with xylene, samples were processed under denaturing conditions with proteinase $\mathrm{K}$ and incubated at $80^{\circ} \mathrm{C}$ for 15 minutes to reverse formalin cross-links. Genomic DNA was removed by passing the lysate through gDNA elimination spin column provided in the kit. Sample was placed in a spin column, washed in situ, and eluted in $30 \mu$ l RNase free water. Approximately $1 \mu \mathrm{g}$ of RNA with $\mathrm{A}_{260} / \mathrm{A}_{280} \sim 2$ was subjected to reverse transcription using Quantiscript reverse transcription kit (Qiagen) following manufacturer's protocol. RNA expression of RASSF1A, APC and MGMT was determined by real time-PCR (Bio-Rad) using SYBR green using specific primers. Primer sequences are given in Additional file 2: Table S2.

\section{Statistical analysis}

Statistical analysis was carried out using SPSS (version 19). The statistical tests used to evaluate the difference in the promoter methylation of candidate genes among normal bladder mucosa, non-invasive and invasive urothelial bladder cancer were Kruskal-Wallis and Mann-Whitney-U. Difference in the RNA expression between muscle invasive (high grade) and non muscle invasive (low grade) urothelial bladder cancer was evaluated using Wilcoxon signed rank test. Paired $T$-test was used to evaluate if there is any difference in the findings of promoter methylation status using paraffin embedded blocks versus blood samples. All p-values $<0.01$ were considered statistically significant. The association between the promoter methylation status and patients' survival (Overall and recurrence free) was studied applying Kaplan-Meier survival plots.

\section{Additional files}

Additional file 1: Table S1. Primer sequences for the tumor suppressor genes included in the study (Xu et al. 2004).

Additional file 2: Table S2. Primer Sequences for RASSF1A, APC and

MGMT real time RT-PCR analysis.

\section{Abbreviations}

APC: Adenomatous polyposis coli; CDH1: Cadherin1; DAPK: Death associated protein kinase; FFPE: Formalin fixed paraffin embedded; FHIT: Fragile histidine triad; MGMT: O-6-Methylguanine-DNA methyltransferase; PTCH: Protein patched homolog 1; PTEN: Phosphatase and tensin homologue deleted on chromosome 10; RASSF1A: Ras- associated domain family 1A; RB1: Retinoblastoma 1;

TSC1: Tuberous sclerosis 1; TURBT: Transurethral resection of bladder tumor.

\section{Competing interest}

The authors declare that they have no competing interest.

\section{Authors' contribution}

SB collected the samples, carried out the experimental work and drafted the manuscript. SAQ analyzed the results and finalized the manuscript. SP helped in the acquisition and interpretation of data. FA provided the plasma samples, analyzed the results and reviewed the manuscript. All authors read and approved the final manuscript.

\section{Acknowledgements}

This work was supported by grant from Higher Education Commission (HEC) Pakistan. We are grateful to Dr. Ahmed Yaqinuddin for his intellectual input on experimental design.

\section{Author details}

${ }^{1}$ Office of Research and Graduate Studies, Aga Khan University, Stadium Road, Karachi 74800, Pakistan. ${ }^{2}$ Department of Biology, Syed Babar Ali School of Science and Engineering, Lahore University of Management Sciences, Sector-U, D.H.A., Lahore 54792, Pakistan. ${ }^{3}$ Department of Microbiology and Pathology, Aga Khan University, Stadium Road, Karachi 74800, Pakistan. ${ }^{4}$ Department of Surgery, Aga Khan University, Stadium Road, Karachi 74800, Pakistan.

Received: 9 November 2013 Accepted: 24 February 2014

Published: 5 April 2014

\section{References}

Belinsky SA, Klinge DM, Dekker JD, Smith MW, Bocklage TJ, Gilliland FD, Crowell RE, Karp DD, Stidley CA, Picchi MA (2005) Gene promoter methylation in plasma and sputum increases with lung cancer risk. Clin Cancer Res 11(18):6505-6511 Berrada N, Amzazi S, Ameziane El Hassani R, Benbacer L, El Mzibri M, Khyatti M, Chafiki J, Abbar M, Al Bouzidi A, Ameur A, Attaleb M (2012) Epigenetic alterations of adenomatous polyposis coli (APC), retinoic acid receptor beta (RARbeta) and survivin genes in tumor tissues and voided urine of bladder cancer patients. Cell Mol Biol (Noisy-le-grand) Suppl.58:OL1744-OL1751

Bhagat R, Chadaga S, Premalata CS, Ramesh G, Ramesh C, Pallavi VR, Krishnamoorthy $L$ (2012) Aberrant promoter methylation of the RASSF1A and APC genes in epithelial ovarian carcinoma development. Cell Oncol (Dordr) 35(6):473-479

Cairns P (2007) Gene methylation and early detection of genitourinary cancer: the road ahead. Nat Rev Cancer 7(7):531-543

Catto JW, Azzouzi AR, Rehman I, Feeley KM, Cross SS, Amira N, Fromont G, Sibony M, Cussenot O, Meuth M, Hamdy FC (2005) Promoter hypermethylation is associated with tumor location, stage, and subsequent progression in transitional cell carcinoma. J Clin Oncol 23(13):2903-2910

Chan MW, Chan LW, Tang NL, Tong JH, Lo KW, Lee TL, Cheung HY, Wong WS, Chan PS, Lai FM, To KF (2002) Hypermethylation of multiple genes in tumor tissues and voided urine in urinary bladder cancer patients. Clin Cancer Res 8(2):464-470

Chang LL, Yeh WT, Yang SY, Wu WJ, Huang CH (2003) Genetic alterations of p16INK4a and p14ARF genes in human bladder cancer. J Urol 170(2 Pt 1):595-600

Dominguez G, Carballido J, Silva J, Silva JM, García JM, Menéndez J, Provencio M, España P, Bonilla F (2002) p14ARF promoter hypermethylation in plasma DNA as an indicator of disease recurrence in bladder cancer patients. Clin Cancer Res 8(4):980-985 
Dulaimi E, Uzzo RG, Greenberg RE, Al-Saleem T, Cairns P (2004) Detection of bladder cancer in urine by a tumor suppressor gene hypermethylation panel. Clin Cancer Res 10(6):1887-1893

Gao T, Wang S, He B, Pan Y, Song G, Gu L, Chen L, Nie Z, Xu Y, Li R (2012) The association of RAS association domain family Protein1A (RASSF1A) methylation states and bladder cancer risk: a systematic review and meta-analysis. PLoS One 7(11):e48300

Hesson LB, Cooper WN, Latif F (2007) The role of RASSF1A methylation in cancer. Dis Markers 23(1-2):73-87

Hoque MO, Begum S, Topaloglu O, Chatterjee A, Rosenbaum E, Van Criekinge W, Westra WH, Schoenberg M, Zahurak M, Goodman SN, Sidransky D (2006) Quantitation of promoter methylation of multiple genes in urine DNA and bladder cancer detection. J Natl Cancer Inst 98(14):996-1004

IARC (2013) Cancer epidemiology database. Cancer Mondial International Agency for Research on Cancer. www-dep.iarc.fr/ Date accessed: 24 August 2013

Jeronimo C, Henrique R, Hoque MO, Mambo E, Ribeiro FR, Varzim G, Oliveira J, Teixeira MR, Lopes C, Sidransky D (2004) A quantitative promoter methylation profile of prostate cancer. Clin Cancer Res 10(24):8472-8478

Jha AK, Nikbakht M, Jain V, Capalash N, Kaur J (2012) p16(INK4a) and p15(INK4b) gene promoter methylation in cervical cancer patients. Oncol Lett 3(6):1331-1335

Jiang Y, Cui L, Chen WD, Shen SH, Ding LD (2012) The prognostic role of RASSF1A promoter methylation in breast cancer: a meta-analysis of published data. PLoS One 7(5):e36780

Klaus A, Birchmeier W (2008) Wnt signalling and its impact on development and cancer. Nat Rev Cancer 8(5):387-398

Knowles MA (2007) Tumor suppressor loci in bladder cancer. Front Biosci 12:2233-2251

Koutsimpelas D, Pongsapich W, Heinrich U, Mann S, Mann WJ, Brieger J (2012) Promoter methylation of MGMT, MLH1 and RASSF1A tumor suppressor genes in head and neck squamous cell carcinoma: pharmacological genome demethylation reduces proliferation of head and neck squamous carcinoma cells. Oncol Rep 27(4):1135-1141

Krassenstein R, Sauter E, Dulaimi E, Battagli C, Ehya H, Klein-Szanto A, Cairns P (2004) Detection of breast cancer in nipple aspirate fluid by CpG island hypermethylation. Clin Cancer Res 10(1 Pt 1):28-32

Le Frere-Belda MA, Cappellen D, Daher A, Gil-Diez-de-Medina S, Besse F, Abbou CC, Thiery JP, Zafrani ES, Chopin DK, Radvanyi F (2001) p15(INK4b) in bladder carcinomas: decreased expression in superficial tumours. Br J Cancer 85(10):1515-1521

Liu L, Kron KJ, Pethe W, Demetrashvili N, Nesbitt ME, Trachtenberg J, Ozcelik H, Fleshner NE, Briollais L, van der Kwast TH, Bapat B (2011) Association of tissue promoter methylation levels of APC, TGFbeta2, HOXD3 and RASSF1A with prostate cancer progression. Int J Cancer 129(10):2454-2462

Ludwig JA, Weinstein JN (2005) Biomarkers in cancer staging, prognosis and treatment selection. Nat Rev Cancer 5(11):845-856

Maruyama R, Toyooka S, Toyooka KO, Harada K, Virmani AK, Zöchbauer-Müller S, Farinas AJ, Vakar-Lopez F, Minna JD, Sagalowsky A, Czerniak B, Gazdar AF (2001) Aberrant promoter methylation profile of bladder cancer and its relationship to clinicopathological features. Cancer Res 61(24):8659-8663

Meng W, Huebner A, Shabsigh A, Chakravarti A, Lautenschlaeger T (2012) Combined RASSF1A and RASSF2A promoter methylation analysis as diagnostic biomarker for bladder cancer. Mol Biol Int 2012:701814

Munoz J, Inda Mdel M, Lázcoz P, Zazpe I, Fan X, Alfaro J, Tuñón T, Rey JA, Castresana JS (2012) Promoter methylation of RASSF1A associates to adult secondary glioblastomas and pediatric glioblastomas. ISRN Neurol 2012:576578

Topaloglu O, Hoque MO, Tokumaru Y, Lee J, Ratovitski E, Sidransky D, Moon CS (2004) Detection of promoter hypermethylation of multiple genes in the tumor and bronchoalveolar lavage of patients with lung cancer. Clin Cancer Res 10(7):2284-2288

Xu XL, Yu J, Zhang HY, Sun MH, Gu J, Du X, Shi DR, Wang P, Yang ZH, Zhu JD (2004) Methylation profile of the promoter $\mathrm{CpG}$ islands of 31 genes that may contribute to colorectal carcinogenesis. World J Gastroenterol 10(23):3441-3454

Yates DR, Rehman I, Abbod MF, Meuth M, Cross SS, Linkens DA, Hamdy FC, Catto JW (2007) Promoter hypermethylation identifies progression risk in bladder cancer. Clin Cancer Res 13(7):2046-2053

doi:10.1186/2193-1801-3-178

Cite this article as: Bilgrami et al:: Promoter hypermethylation of tumor suppressor genes correlates with tumor grade and invasiveness in patients with urothelial bladder cancer. SpringerPlus 2014 3:178.

\section{Submit your manuscript to a SpringerOpen ${ }^{\circ}$ journal and benefit from:}

- Convenient online submission

- Rigorous peer review

- Immediate publication on acceptance

- Open access: articles freely available online

- High visibility within the field

- Retaining the copyright to your article

Submit your next manuscript at $>$ springeropen.com 